\title{
CONSTRUCTING THE COMPREHENSIVE SUBSURFACE STRUCTURE OF LANYANG PLAIN
}

\author{
Chih-Hao Hsu \\ Department of Harbor and River Engineering, National Taiwan Ocean University, Keelung, Taiwan, R.O.C \\ Sao-Jeng Chao \\ Department of Civil Engineering, National Ilan University, Ilan, Taiwan, R.O.C, Chao@niu.edu.tw \\ Shuh-Gi Chern \\ Department of Harbor and River Engineering, National Taiwan Ocean University, Keelung, Taiwan, R.O.C. \\ Howard Hwang \\ Graduate Institute of Architecture and Sustainable Planning, National Ilan University, Ilan, Taiwan, R.O.C.
}

Follow this and additional works at: https://jmstt.ntou.edu.tw/journal

Part of the Ocean Engineering Commons

\section{Recommended Citation}

Hsu, Chih-Hao; Chao, Sao-Jeng; Chern, Shuh-Gi; and Hwang, Howard (2012) "CONSTRUCTING THE COMPREHENSIVE SUBSURFACE STRUCTURE OF LANYANG PLAIN," Journal of Marine Science and Technology: Vol. 20: Iss. 2, Article 10.

DOI: $10.51400 / 2709-6998.1838$

Available at: https://jmstt.ntou.edu.tw/journal/vol20/iss2/10

This Research Article is brought to you for free and open access by Journal of Marine Science and Technology. It has been accepted for inclusion in Journal of Marine Science and Technology by an authorized editor of Journal of Marine Science and Technology. 


\section{CONSTRUCTING THE COMPREHENSIVE SUBSURFACE STRUCTURE OF LANYANG PLAIN}

Acknowledgements

The authors would like to thank the National Center for Earthquake Engineering Research (NCREE) for providing the boring log data pertinent to the sites of strong motion stations in the llan area 


\title{
CONSTRUCTING THE COMPREHENSIVE SUBSURFACE STRUCTURE OF LANYANG PLAIN
}

\author{
Chih-Hao Hsu ${ }^{1}$, Sao-Jeng Chao ${ }^{2}$, Shuh-Gi Chern ${ }^{1}$, and Howard Hwang ${ }^{3}$
}

Key words: Lanyang Plain, shear wave velocity, subsurface structure.

\begin{abstract}
This study presents an integral approach to construct a comprehensive subsurface structure of Lanyang Plain. It is well known that geophysicists and engineers use different techniques to investigate the subsurface structure, and each of these techniques has its own advantages. Therefore, in this study, the excellent results from these two fields are selected and combined to provide a comprehensive profile of the subsurface structure of Lanyang Plain. In this study, the subsurface information on nine recording stations and digital boundary lines of Lanyang Plain based on the digital geologic map published by the Central Geological Survey are utilized to create a three dimensional surface structure of Lanyang Plain. On the other hand, data on 771 boring logs in the Ilan area are collected from many agencies. Using these two data bases, a comprehensive subsurface structure of Lanyang Plain is established by combining the subsurface data inferred from geophysicist's investigation and the detailed boring log data close to ground surface from engineer's endeavor. The results of this study can be utilized in the field of disaster reduction, such as the calculation of ground response subject to earthquakes using the SHAKE computer program and then the evaluation of safety of buildings in a seismic event.
\end{abstract}

\section{INTRODUCTION}

The Ilan County in Taiwan is surrounded by mountains on three sides, Hsuehshan Mountain Range in the northwestern side and Central Mountain Range in the southeastern side, and

Paper submitted 03/12/10; revised 11/16/10; accepted 12/16/10. Author for correspondence: Sao-Jeng Chao (e-mail: Chao@niu.edu.tw).

${ }^{I}$ Department of Harbor and River Engineering, National Taiwan Ocean University, Keelung, Taiwan, R.O.C.

${ }^{2}$ Department of Civil Engineering, National Ilan University, Ilan, Taiwan, R.O.C.

${ }^{3}$ Graduate Institute of Architecture and Sustainable Planning, National Ilan University, Ilan, Taiwan, R.O.C. the county faces the Pacific Ocean in the east. The Hsuehshan Mountain Range is mainly composed of slightly metamorphosed slate and argillite, while the Central Mountain Range is mainly composed of argillite, phyllite, and slate. The Lanyang Plain is a sedimentary deposit from Lanyang River and its branches. The shape of Lanyang Plain is an isosceles triangle with boundary length of 30 kilometer and the total area of Lanyang Plain is about 360 square kilometer. The Lanyang Plain is covered by a Quaternary alluvium layer over other rock layers. The thickness of layers and the depth to the basement rock are varying from points to points in the Lanyang Plain. As a result, when an earthquake occurs, seismic waves will be modified as the waves pass through the subsurface layers, that is, the amplitude of seismic waves may be amplified and the frequency contents of seismic waves may also be modified. As a consequence, the safety of buildings may be affected. In view of this phenomenon, the subsurface structure of Lanyang Plain is worthy to be investigated.

Geophysicists investigate the physical properties of subsurface layers by using instrumental measurements of seismic wave, gravity, and magnetic force, etc. The investigation results in a rough division of subsurface layers, in particular, the subsurface layer close to the ground surface. On the other hand, engineers explore the subsurface layers by drilling boreholes to provide detailed information including the type of soil, layer thickness, standard penetration test N-value (SPT-N), groundwater level, etc. Because of drilling capacity and available resources, the drilling is usually limited to soil layers close to the ground surface, and the deeper soil and rock layers may not be explored. From the above explanation, it is evident that geophysicists and engineers use different techniques to investigate the subsurface structure, and each of these techniques has its own advantages. Therefore, in this study, the excellent results from these two fields are selected and combined to provide a comprehensive profile of the subsurface structure of Lanyang Plain, that is, a comprehensive subsurface structure of Lanyang Plain is established by combining the subsurface data inferred from geophysicist's investigation and the detailed boring log data from engineer's endeavor. The results of this study can be utilized in the field of disaster reduction, such as the calculation of ground response subject to earthquakes using the SHAKE computer program and then 


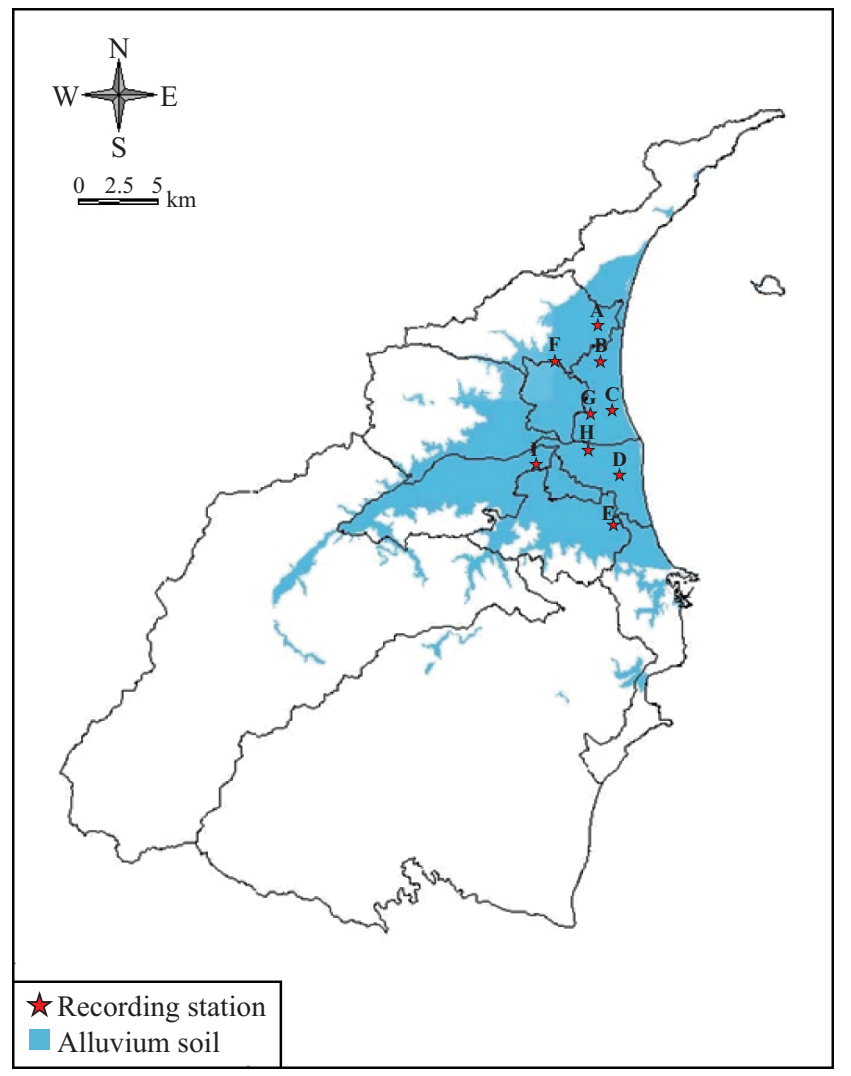

Fig. 1. Positions of nine recording stations in the Lanyang Plain set up by Huang [5].

the evaluation of safety of buildings in a seismic event.

\section{ESTABLISHMENT OF SUBSURFACE STRUCTURE BY GEOPHYSICAL METHODS}

The studies on subsurface structure of Lanyang Plain have been carried out since 1970s. Chiang [2] shot 8 reflective profiles in Lanyang Plain and 4 reflective profiles in the neighborhood of Lotong. He concluded that a Pleistocene formation in the form of a half moon is sandwiched between an alluvium layer and basement rock in Lanynag Plain. From the results of seismic exploration in Lotong area, Wen and Yeh [6] suggested that the subsurface structure can be divided into four layers including ground surface layer, alluvium layer, Pleistocene formation and basement rock. Based on the surface wave velocity dispersion curves in Lotong area, Huang and Yeh [4] suggested that the strata from ground surface to a depth of 300 meter in Lotong area may be divided into two layers. Using microtremors recorded at nine survey stations in Lanyang Plain, Huang [5] determined the shear wave velocity structure at these stations.

As mentioned above, Huang [5] set up nine recording stations in Lanyang Plain (Fig. 1). By using the frequency-wave number method, the microtremors collected at these stations were used to determine the surface wave velocity dispersion
Table 1. Layer depths and shear wave velocities of Lanyang Plain [5].

\begin{tabular}{|c|c|c|c|c|c|c|}
\hline \multirow{4}{*}{ Stations } & \multicolumn{2}{|c|}{$\begin{array}{c}\text { Layer 1 } \\
\text { (Alluvium layer) }\end{array}$} & \multicolumn{2}{c|}{$\begin{array}{c}\text { Layer 2 } \\
\text { (Pleistocene } \\
\text { formation) }\end{array}$} & \multicolumn{2}{c|}{$\begin{array}{c}\text { Layer 3 } \\
\text { (Lushan layer) }\end{array}$} \\
\cline { 2 - 7 } & $\begin{array}{c}\text { Depth } \\
(\mathrm{km})\end{array}$ & $\begin{array}{c}\text { Vs } \\
(\mathrm{km} / \mathrm{s})\end{array}$ & $\begin{array}{c}\text { Depth } \\
(\mathrm{km})\end{array}$ & $\begin{array}{c}\mathrm{Vs} \\
(\mathrm{km} / \mathrm{s})\end{array}$ & $\begin{array}{c}\text { Depth } \\
(\mathrm{km})\end{array}$ & $\begin{array}{c}\text { Vs } \\
(\mathrm{km} / \mathrm{s})\end{array}$ \\
\hline $\mathrm{A}$ & 0.065 & 0.22 & 0.61 & 0.81 & $1.00 \uparrow$ & 2.05 \\
\hline $\mathrm{B}$ & 0.055 & 0.20 & 0.52 & 0.65 & $0.90 \uparrow$ & 1.71 \\
\hline $\mathrm{C}$ & 0.090 & 0.22 & 0.72 & 0.76 & $0.70 \uparrow$ & 1.91 \\
\hline $\mathrm{D}$ & 0.100 & 0.25 & 0.42 & 0.69 & $0.90 \uparrow$ & 1.88 \\
\hline $\mathrm{E}$ & 0.100 & 0.35 & 0.43 & 0.92 & $0.95 \uparrow$ & 2.26 \\
\hline $\mathrm{F}$ & 0.045 & 0.17 & 0.48 & 0.76 & $0.90 \uparrow$ & 1.88 \\
\hline $\mathrm{G}$ & 0.065 & 0.22 & 0.51 & 0.66 & $0.90 \uparrow$ & 1.70 \\
\hline $\mathrm{H}$ & 0.095 & 0.24 & 0.62 & 0.87 & $0.70 \uparrow$ & 2.33 \\
\hline $\mathrm{I}$ & 0.070 & 0.22 & 0.47 & 0.86 & $0.90 \uparrow$ & 2.14 \\
\hline
\end{tabular}

curves and then the subsurface shear wave velocity structures at the recording stations (Table 1). As shown in the table, the subsurface structure of Lanyang Plain is divided into three layers. From top down, they are alluvium layer, Pleistocene formation, and Lushan layer. The interface between alluvium layer and Pleistocene formation is called velocity interface 1 and the interface between Pleistoncene formation and Lushan layer is denoted as velocity interface 2 .

In this study, the subsurface information established by Huang [5] and digital boundary line data from the digital geological map published by Central Geological Survey are utilized to create a three dimensional subsurface structure of Lanyang Plain. The procedure is described as follows:

1. The nine recording stations are located digitally using a GIS software ArcGIS. In addition, the depths of velocity interfaces 1 and 2 as well as the shear wave velocities of layers are implemented as attribute data at these recording stations.

2. The digital information of the boundary lines of Lanyang Plain is taken from the digital geologic map in the Ilan area published by Central Geological Survey (Fig. 2). The depths of velocity interfaces 1 and 2 at the boundary lines are set as zero.

3. A grid system with spacing of 300 meter is applied to the study area. As a result, a total of $100 \times 100$ grid points are created to cover in the study area.

4. The depths of velocity interfaces 1 and 2 at the grid points are determined based on the data mentioned above by using the Kriging interpolation algorithm implemented in the software of SURFER [3]. The contour maps of the velocity interfaces 1 and 2 are shown in Figs. 3 and 4, respectively. Furthermore, on the basis of these data, digital ground model analyses are performed to establish the three-dimensional (3D) topographic maps. The 3D topographic maps of the velocity interfaces 1 and 2 are shown in Figs. 5 and 6, respectively. 


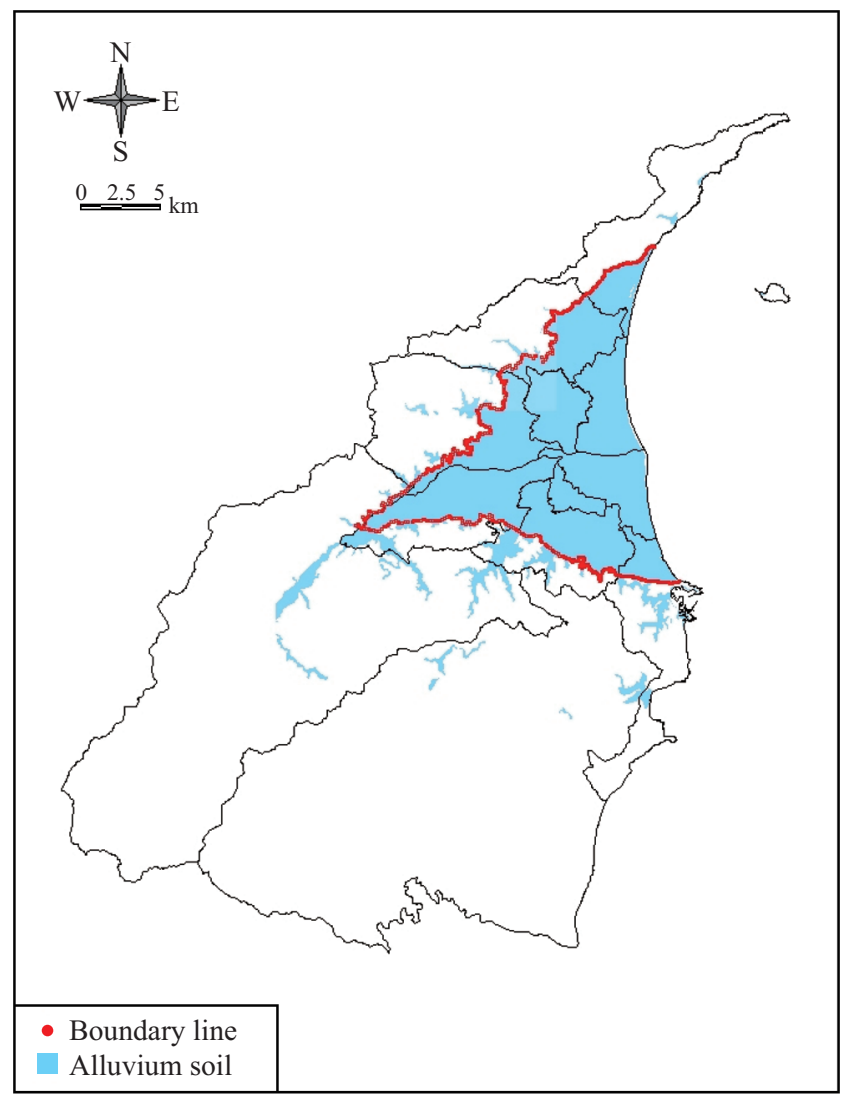

Fig. 2. Boundary lines of Lanyang Plain.

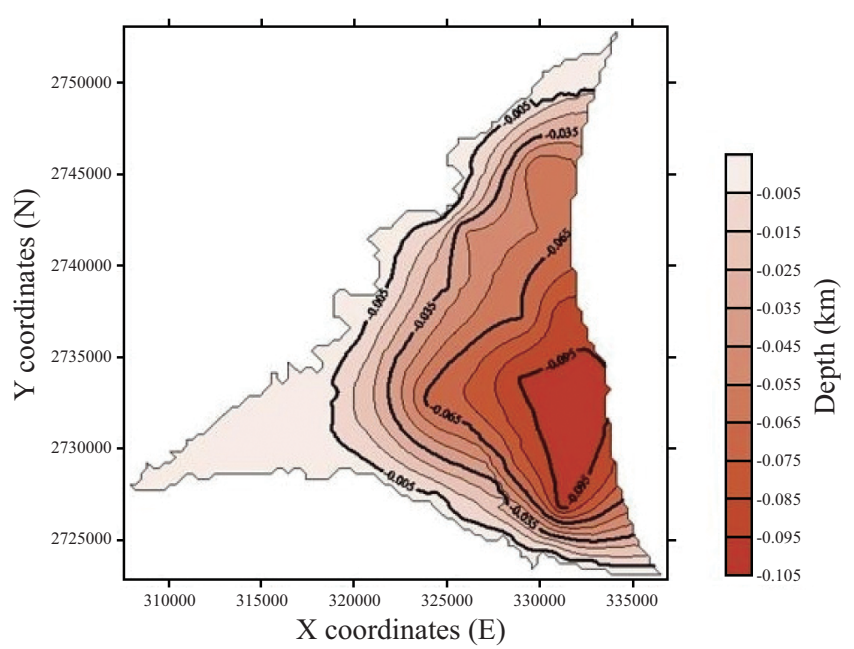

Fig. 3. Contour map of the depth of velocity interface 1 of Lanyang Plain.

5. As shown in Table 1, the shear wave velocities vary only slightly in the same layer in Lanyang Plain. Thus, the shear wave velocity on the boundary lines of Lanyang Plain is set as the average value of shear wave velocity in that layer. Then, the shear wave velocity values at the nine recording stations and on the boundary lines are used to determine the shear wave velocity values at the grid points by using the same Kriging algorithm.

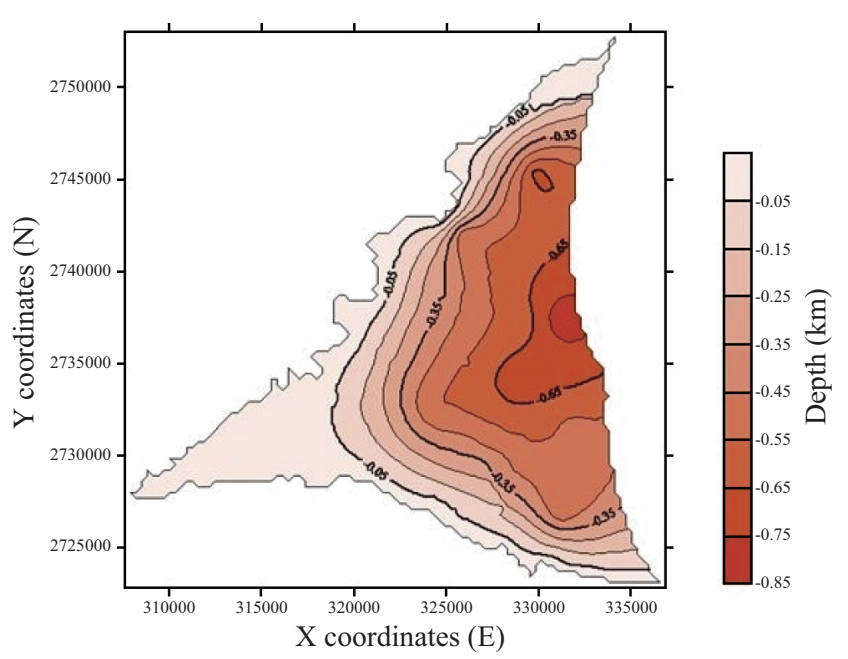

Fig. 4. Contour map of the depth of velocity interface 2 of Lanyang Plain.

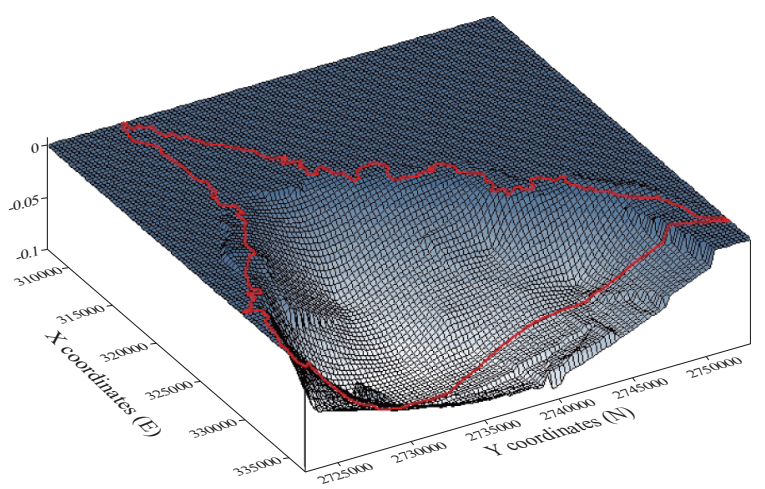

Fig. 5. Topographic map of the depth of velocity interface 1 of Lanyang Plain.

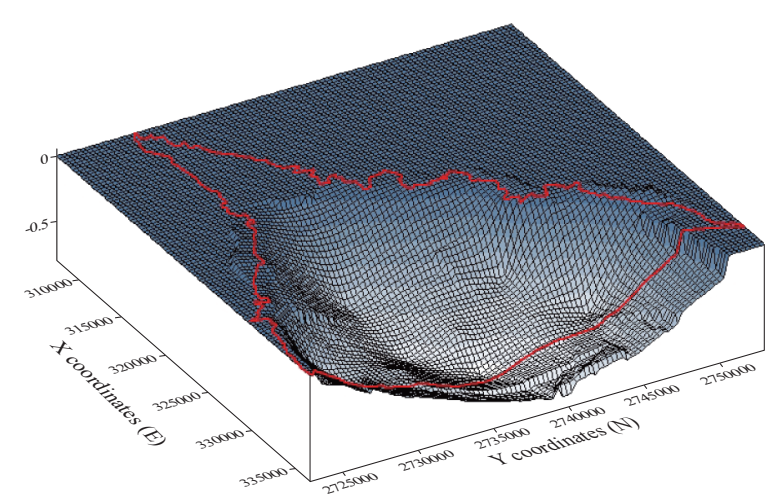

Fig. 6. Topographic map of the depth of velocity interface 2 of Lanyang Plain.

As an illustration of the three dimensional subsurface structure of Lanyang Plain established by this study, two profile lines are drawn as shown in Fig. 7. Two profile lines are profile AA' from west to east and profile BB' from north to south. The profile AA' and profile BB' are shown in Fig. 8 and 9 , respectively. As being seen from these profiles, the depth of the alluvium layer increases from west to east and the 


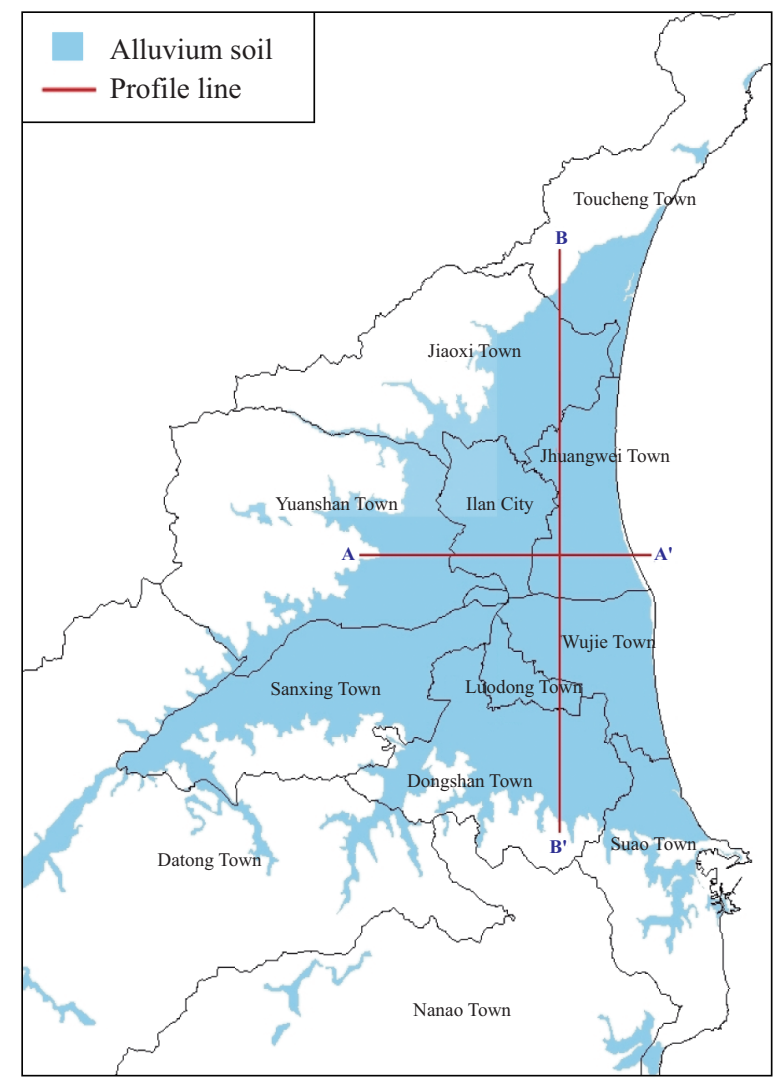

Fig. 7. Positions of two profile lines in Lanyang Plain.

thickness is less than 100 meters. The depth of Pleistocene formation also increases from west to east, but the deepest area of Pleistocene formation in the north-south direction (profile BB') is in the middle of Lanyang Plain. The thickness of Pleistocene formation is less than 0.8 kilometer.

\section{CONSTRUCTION OF SUBSURFACE STRUCTURE BY BORING LOG DATA}

In this study, hundreds of representative boring log data within the Lanyang Plain are collected for the construction of the subsurface structure close to the ground level. A brief description of these boring log data is as follows:

The National Center for Earthquake Engineer Research (NCREE) has initiated a project to explore the characteristics of the sites where the strong motion instruments have been installed. The boring log data of 33 sites in Ilan County are obtained for the use in this study. With the assistance of the co-author, NCREE has also compiled 572 boring log data from engineering projects carried out in Ilan County. These boring $\log$ data are also utilized in this study. In recent years, several buildings have been constructed in the campus of the National Ilan University. From these projects, 81 boring logs have been collected. Furthermore, a project on investigating the expected damage to school buildings in Ilan County has been carried out by co-authors. As a result, 85 boring logs have

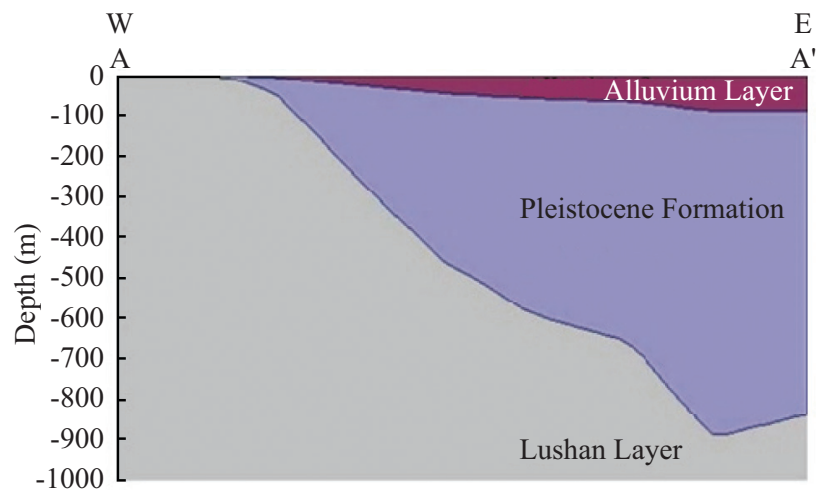

(m)

Fig. 8. Profile AA' (west to east) of subsurface structure of Lanyang Plain.

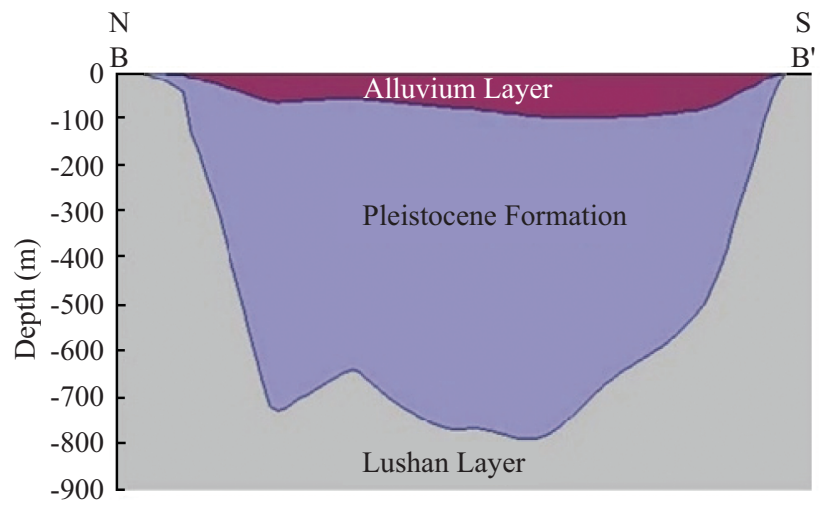

(m)

Fig. 9. Profile BB' (north to south) of subsurface structure of Lanyang Plain.

been collected. These boring logs are also utilized in this study. The numbers of boring log data utilized in this study are summarized in Table 2.

Following the format specified by the NCREE (Wu et al. [7]), the collected boring log data are divided into two tables in an excel file. The information of first table includes the sample number, position coordinates of borehole, ground elevation, groundwater depth, drilling date, total depth, drilling method, drilling company, and drilling operators. The information of second table includes the standard penetration test $\mathrm{N}$ value (SPT-N), soil classification, particle size distribution, moist unit weight, water content, liquid limit, and plastic limit. As shown in Table 2, a total of 771 boring log data are collected and can be utilized for the construction of subsurface structure of Lanyang Plain.

\section{ESTABLISHMENT OF COMPREHENSIVE SUBSURFACE STRUCTURE OF LANGYANG PLAIN}

In this study, the three layers of subsurface structure established by geophysical method and collected boring log data 
Table 2. Boring log data collected for this study.

\begin{tabular}{|l|l|c|}
\hline \multicolumn{1}{|c|}{ Data Source } & \multicolumn{1}{|c|}{ Content } & Numbers \\
\hline $\begin{array}{l}\text { Boring log data at strong motion stations in Ilan } \\
\text { area compiled by NCREE }\end{array}$ & $\begin{array}{l}\text { Position coordinates of borehole, ground elevation, groundwater depth, } \\
\text { total depth, drilling method and properties of soils }\end{array}$ & 33 \\
\hline $\begin{array}{l}\text { Boring log data in Ilan County compiled by } \\
\text { NCREE }\end{array}$ & $\begin{array}{l}\text { Position coordinates of borehole, ground elevation, groundwater depth, } \\
\text { total depth and properties of soils }\end{array}$ & 572 \\
\hline $\begin{array}{l}\text { Boring log data in the campus of the National Ilan } \\
\text { University }\end{array}$ & $\begin{array}{l}\text { Position coordinates of borehole, ground elevation, groundwater depth, } \\
\text { total depth, drilling method and properties of soils }\end{array}$ & 81 \\
\hline $\begin{array}{l}\text { Boring log data from Ilan County schools com- } \\
\text { piled by the National Ilan University }\end{array}$ & $\begin{array}{l}\text { Position coordinates of borehole, ground elevation, groundwater depth, } \\
\text { total depth, drilling method and properties of soils }\end{array}$ & 85 \\
\hline Total & & 771 \\
\hline
\end{tabular}

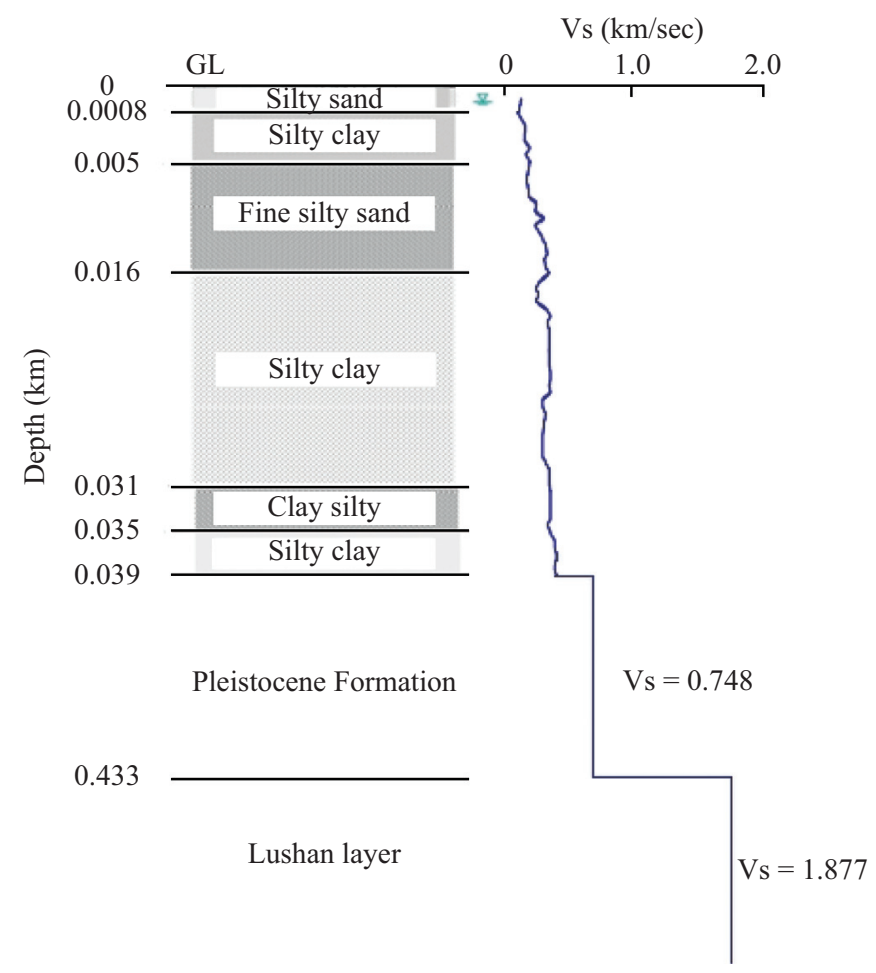

Fig. 10. Comprehensive subsurface structure at IanB030 site in Ilan County.

are combined to create a comprehensive subsurface structure of Lanyang Plain. Based on Huang's [5] findings, the strata of Lanyang Plain are divided into three layer from the top down: alluvium layer, Pleistocene formation, and Lushan layer. Most of the boring log data are from boreholes with a depth commensurate to the depth of the alluvium layer; therefore, the boring log data are used to replace the alluvium layer. If the depth of boring $\log$ is shorter than the depth of the velocity interface between the alluvium layer and the Pleistocene formation, the last layer of the boring log is extended downward to this velocity interface. It is noted that all information including the shear wave velocity of the last layer of the boring $\log$ are assigned to the extended area. In this paper, boring log IanB030 is used to illustrate this procedure. The depth of this borehole is 40 meters. At this location the depth of the alluvium layer is 39 meters. Thus, the upper 39 meters of boring $\log$ are used to replace the alluvium layer. A complete profile of subsurface structure including a profile of shear wave velocity is shown in Fig. 10.

\section{UTILIZATION OF DATABASE OF SUBSURFACE STRUCTURE OF LANYANG PLAIN}

As shown in Table 2, 771 boring log data in Ilan area have been collected for this study. The data in the Microsoft Excel format (.dbf) are stored in the Ilan Boring Log Database file. In addition, these data have also been implemented as a GIS database using ArcGIS. The pertinent data information such as type of soil, layer thickness, standard penetration test $\mathrm{N}$ value (SPT-N), etc. have been compiled as attribute data. Thus, these data can be utilized with the assistance of ArcGIS. On the other hand, a three-dimensional three-layer subsurface structure of Lanyang Plain has been established as described in Section II. The pertinent data are created at $100 \times 100$ grid points. These data can only be utilized with the help of the software SURFER. Because of the limitation of computer software, the user may have difficulty in querying data (Chao et al. [1]). Thus, a graphic user interface for the subsurface structure of Lanyang Plain has been developed by using Visual Studio dot Net 2003 with the database connected via Microsoft Data Access Components (MDAC). The database in the Microsoft Access format (.mdb) are stored in the LYPSS file. With the assistance of the relational index, the data can be queried effectively. Furthermore, the graphic user interface can be used to draw the query results. It is expected that the graphic user interface of subsurface structure of Lanyang Plain can be used in many different fields.

\section{CONCLUSION}

In this study, an integral approach has been proposed to construct a comprehensive subsurface structure of Lanyang Plain. The proposed approach combines the subsurface data inferred from geophysicist's investigation and the detailed 
boring log data close to ground surface from engineer's endeavor to construct the comprehensive subsurface structure of Lanyang Plain. The results of this study can be utilized in the calculation of ground response subject to earthquakes using the SHAKE computer program and then the evaluation of safety of buildings in a seismic event.

\section{ACKNOWLEDGMENTS}

The authors would like to thank the National Center for Earthquake Engineering Research (NCREE) for providing the boring log data pertinent to the sites of strong motion stations in the Ilan area.

\section{REFERENCES}

1. Chao, S. J., Hwang, H., and Hsu, C. H., "A study on three dimensional shallow subsurface structure of Lanyang Plain," Bulletin of College of
Engineering, National Ilan University, Vol. 4, pp. 53-74 (2008). (in Chinese)

2. Chiang, S. C., "Seismic investigation of Lanyang Plain," Bulletin of Mining Technology, Vol. 14, pp. 215-221 (1976). (in Chinese)

3. Golden Software Inc., SURFER User's Guide, Golden, CO (2002).

4. Huang, W. G. and Yeh, Y. T., "The characteristics of microtremors at the site of SMART1 array," Terrestrial, Atmospheric and Oceanic Sciences, Vol. 1, No. 3, pp. 225-242 (1990).

5. Huang, Y. C., Site Effect and Near Surfaces Wave Velocity Structure in Lanyang Plain, Master Thesis, National Central University, Chungli, Taiwan (2003). (in Chinese)

6. Wen, K. L. and Yeh, Y. T., Establish Shallow Subsurface By Strong Motion Array (SMART1) in Lotong Area, Technical Report, Institute of Earth Science, Academia Sinica (1983). (in Chinese)

7. Wu, B. R., Yeh, C. H., Shieh, M. Y., and Ke, M. V., "Database and analytical modeling of liquefaction and landslide hazards", Proceedings of 2004 Taiwan Earthquake Loss Estimation System (TELES) Seminar, Report NCREE-04-018, National Center for Research on Earthquake Engineering, Taipei, Taiwan, pp. 51-74 (2004). (in Chinese) 